significantly had declined trends in study period $(p<0.05)$. Trends of age-specific incidence rates for both of pulmonary, extrapulmonary, also for male and female cases were increased as $\chi^{2}=1265 ; \chi^{2}=307.7$, $\mathrm{p}=0.0001$ and $\chi^{2}=931 ; \chi^{2}=582, \mathrm{p}=0.0001$, respectively. Considering the national tuberculosis standard index, smear positive notification rate was in the range of expected levels $(58 \%-68 \%)$, but extrapulmonary incidence rates were more than the expected level.

Conclusion Regarding the higher incidence rates of tuberculosis in the southern regions of West Azerbaijan province of Iran, and despite of declined trends at some of districts at this region, it seems that more control and prevention activities are still needed, especially for the lower socioeconomic populations. Comparison of the demographic, socioeconomic status and specific incidence rates, revealed that the epidemiologic patterns of $\mathrm{TB}$ at this province have shifted from developing to developed countries status.

\section{P2-435 SPECIFIC RISK FACTORS ASSOCIATED WITH CORONARY HEART DISEASE IN INDIANS}

doi:10.1136/jech.2011.142976l.65

P Joshi, R Kumari, ${ }^{*}$ M Z Idris, N Ahmad, R K Saran, S M Natu. KG Medical University, Lucknow, Uttar Pradesh, India

Background The rapidly increasing burden of noncommunicable diseases is a key determinant of global public health. Coronary artery disease $(\mathrm{CAD})$ is the largest killer globally.

Objective To study the distribution and the effect of specific risk factors on Coronary Heart Disease in the adult population.

Study design Cross sectional study.

Sample size 1101 subjects.

Study area Rural and urban area of Lucknow District, Uttar Pradesh, India.

Study tool and Data collection Pre-designed and pre-tested interview in relation to smoking, passive tobacco smoking, alcohol consumption, physical activity, Blood pressure, BMI, central obesity, dietary history, mental status, diabetes, lipid profile was assessed.

Results The prevalence of coronary heart disease in the total study sample came out to be $7.1 \%$. The prevalence in urban was significantly higher than rural $8.8 \%$ and $3.8 \%$ respectively, $\mathrm{CHD}$ was higher in past smokers $(17.8 \%)$ than nonsmokers $(7.1 \%)$, passive tobacco smoking $(10.7 \%)$, hypertensive subjects $11.2 \%$ as compared to normotensive subjects $5.5 \%$, significant difference was found between overweight (M-9\%, F-20.9\%) and normal subjects (M-6.7\%, F-6.8\%), higher prevalence was observed among subjects having central obesity (M-8.6\%, F-6.4\%), Non vegetarian had higher CHD $(9.9 \%)$ as compare to vegetarian $(6.0 \%)$. CHD was more in subjects having mild depression (12.1\%) than normal subjects (6.5\%). The prevalence was higher in subjects having high total cholesterol (7.6\%) and low HDL level (9.5\%).

Conclusion CHD was higher in smokers, non vegetarian, hypertensive and depressive subjects. There was significant difference between Rural and Urban smokers. Passive tobacco smoking, Alcohol consumption, B.P, BMI, central obesity and overweight was significantly associated with CHD.

\section{P2-436 RURAL-URBAN MIGRATION IN RELATION TO DXA MEASURES OF ADIPOSITY IN INDIA}

\section{doi:10.1136/jech.2011.142976l.66}

${ }^{1} \mathrm{H}$ Kuper, ${ }^{*}{ }^{1} \mathrm{~S}$ Kinra, ${ }^{3} \mathrm{~K}$ V Radhakrishna, ${ }^{2} \mathrm{~A}$ Taylor, ${ }^{3} \mathrm{~B}$ Kulkarni, ${ }^{2} \mathrm{Y}$ Ben-Shlomo, ${ }^{1} S$ Ebrahim. ${ }^{1}$ LSHTM, London, UK; ${ }^{2}$ Bristol University, Bristol, UK; ${ }^{3}$ National Institute of Nutrition, Hyderabad, India

Introduction India is experiencing an epidemic of obesity, diabetes and coronary disease. This epidemic is largely attributed to rapid urbanisation, driven in part by rural-urban migration. The aim of this study is to investigate whether rural-urban migration is related to DXA measures of adiposity within the Hyderabad arm of the Indian Migrant Study.

Methods Migrants of rural origin, their rural dwelling sibs, and those of urban origin together with their urban dwelling sibs were invited to attend for a screening examination. Participants underwent DXA scanning to assess total body fat and abdominal fat. Anthropometric variables were also measured and participants were interviewed.

Results We recruited 253 rural non-migrant rural (RNM), 332 ruralurban migrants (RUM), and 125 urban non-migrant (UNM) participants. Overall, $54 \%$ were male and average age was 48 years. RNM had significantly lower total fat, in terms of kgs of fat and percentage body fat, compared to RUM and UNM among both men (RNM: $14.8 \mathrm{~kg}$ and 22.5\%; RUM: $18.0 \mathrm{~kg}$ and $25.5 \%$; UNM; $18.6 \mathrm{~kg}$ and $25.9 \%$ ) and women (RNM: $20.9 \mathrm{~kg}$ and $35.3 \%$; RUM: $24.7 \mathrm{~kg}$ and $38.3 \%$; UNM; $27.3 \mathrm{~kg}$ and $39.8 \%$ ). Abdominal fat mass was also significantly lower among RNM than the two urban groups in both men and women. The percentage of total body fat in the abdominal region was lower among RNM men than the two urban groups, but this difference was not apparent among women.

Conclusion Migration into urban areas is associated with increased obesity, which may drive other risk factor changes.

\section{P2-437 DISABILITY IN TRAFFIC ACCIDENTS' VICTIMS ADMITTED TO A TRAUMA HOSPITAL IN BELO HORIZONTE, BRAZIL}

doi:10.1136/jech.2011.142976l.67

R Ladeira, ${ }^{*}$ M da Silva, I Starling, A P Santos, E Rocha, K Alves, E Azevedo, G Petri, J D Fialho, C Simao-Filho. Joao XXIII - Hospital - FHEMIG, Belo Horizonte, Minas Gerais, Brazil

Introduction Traffic accidents are an important cause of morbidity and mortality around the world. The aim of this study is describe the characteristics, accident profile and injuries suffered by the victims and the occurrence of sequelae.

Methods The study included traffic accident victims admitted to Joao XXIII Hospital - FHEMIG up to $24 \mathrm{~h}$ after the event between 1 March and 15 July 2008. Patients were also interviewed 12 months after the accident. The study was funded by PPSUS/FAPEMIG.

Results 181 patients were interviewed 1 year after the accident. $85.6 \%$ were male. The age group with the highest number of accidents was the $20-30$ year-olds (47\% of the total). Motorcycle occupants were the most common type of victim-112 (61.9\%). $89.7 \%$ of the patients were not able to work following the accident. Moreover, $40 \%$ were still unable to return to their usual activities 12 months after the accident. $50 \%$ considered their health as good, compared to their health condition one year before and $36.4 \%$ considered their health as worse than the previous year. Around $73 \%$ of the victims presented some kind of sequela one year after the accident, although they were mostly minor.

Conclusions This study showed a predominance of young male motorcycle occupants among traffic accident victims admitted to the hospital. Furthermore, a high proportion of victims were unable to return to work (40\%), even one after the accident. This fact highlights the high burden brought on by traffic accidents.

\section{P2-438 ETHNIC AND AGE DIFFERENCES IN THE INCIDENCE OF TUBERCULOSIS IN BULGARIA}

doi:10.1136/jech.2011.142976l.68

\section{B Levterova, ${ }^{*}$ D Dimitrova. Medical University, Plovdiv, Bulgaria}

One-third of the world's population is infected with TB. TB is debilitating and contagious. Every year, more than 9 million people develop active TB and 1.7 million people die from the disease. In Bulgaria incidence was 25.1/100 000 in 1990. Due to various reasons, 
related to socio-economic changes in the country in the following years a doubling of the cases of tuberculosis up to 49.9/100 000 was observed in 1998. Recently there has been a tendency to arrest and slowly reduce incidence - up to 37.1/100 000 in 2007. One of the most affected groups at risk for the development and spread of tuberculosis in Bulgaria are the people from the Roma community. According to the National Statistical Institute (2001) 9\% of the population identified themselves as Roma. In Bulgaria there is no registration and analysis of health indicators by ethnic groups, therefore the assessment of the health of these communities is difficult. TB in Roma communities is higher than the national average prevalence. The goal of this study was to establish the prevalence and determinants characterising this distribution process. Preventive measures should be targeted at early development and improvement of living and working conditions to overcome social exclusion. Targeted epidemiological studies of morbidity among people in the Roma community, identification of risk factors and the development of preventive strategies are needed to combat tuberculosis.

\section{P2-439 MIGRANTS AND REFUGEES MENTAL HEALTH: A SYSTEMATIC REVIEW}

doi:10.1136/jech.2011.142976l.69

J Lindert, ${ }^{*} 0$ von Ehrenstein, E Brähler. Protestant University, Ludwigsburg, Germany

Introduction Migrants mental health is an issue of concern worldwide. We aimed to review studies on prevalence rates of depression and/or anxiety among refugees and labour migrants; to evaluate associations between the Gross National Product (GNP) of the immigration country and depression and anxiety.

Methods Systematic literature for population based studies reporting prevalence rates of depression and/or anxiety according to DSM- or ICD- criteria; and calculation of combined estimates with the Dersimonian-Laird estimator for proportions with the respective $\mathrm{CI}$.

Results 348 records; with 37 on 35 populations meeting the inclusion criteria. 35 studies were included in the final analysis. Combined prevalence rates for depression among labour migrants were $20 \%$ ( $95 \%$ CI $14 \%$ to $26 \%$ ) vs $44 \%$ (95\% CI $27 \%$ to $62 \%$ ) among refugees; for anxiety among labour migrants $21 \%$ (95\% CI $14 \%$ to $29 \%$ ) vs $40 \%$ among ( $95 \%$ CI $23 \%$ to $49 \%$ ) ( $n=24051$ ). Higher GNP in the country of immigration was related to lower symptom prevalence of depression and/or anxiety in labour migrants; but not in refugees.

Conclusion Depression and/or anxiety in labour migrants and refuges needs to be considered separately. The GNP of the host country appears to be related to better mental health in labour migrants but not in refugees.

\section{P2-440 ORGANISATIONAL AND HEALTH FACTORS AMONG WORKERS AND THEIR SUPERVISORS IN EXPORT PROCESSING ZONES IN THE PHILIPPINES}

doi:10.1136/jech.2011.142976l.70

$\mathrm{J} \mathrm{L}$ Lu. ${ }^{*}$ National Institutes of Health, University of the Philippines Manila, Manila, The Philippines

Introduction We investigated the relationship between organisational/management factors at work with health factors in the manufacturing sector.

Materials and Methods A survey was undertaken in 23 establishments, including 630 workers, and 47 supervisors. In addition, 10 focus group discussions (FGDs) for workers, and 5 FGDs for supervisors were undertaken.
Results Workers and supervisors both reported illnesses and job dissatisfaction. The survey found that the most prevalent issues among workers were: the need to upgrade skills (76.3\%), feeling pressured in doing work (60.5\%), fast paced work (60.5\%), repetitive work $(63 \%)$, and that work is both physically and mentally tiring (59.7\%). Among supervisors the issues raised included: work described as challenging and stimulating (66\%), needing regular upgrading of skills (46.8\%), and needing literature on information technology (31.9\%). Focus group discussions showed that workers and supervisors were confronted with stress, fast-paced work, the need to upgrade skills in order to accommodate new information technology into the work production, fatigue, re-engineering and downsizing by management, low job control and difficult worker-supervisor relationship.

Conclusions This study was able to show that health of workers and supervisors is affected by both organisational and management factors at work.

\section{P2-441 OCCUPATIONAL HAZARDS AND ILLNESSES OF FILIPINO WOMEN WORKERS IN EXPORT PROCESSING ZONES}

doi:10.1136/jech.2011.142976l.71

S F Lu, J L Lu.* National Institutes of Health, University of the Philippines Manila, Manila, The Philippines

This was a baseline study on the occupational exposures and health problems among women workers in Export Processing Zone with employers from foreign multinationals such as Americans, Europeans Japanese, Chinese, and Indians. Physical, chemical and ergonomic hazards were evaluated and measured through workplace ambient monitoring, survey questionnaires, and interviews among 24 industries, and 500 respondents (majority were female at $88.8 \%$ ). The top 5 hazards were ergonomic hazards $(72.2 \%)$, heat $(66.6 \%)$, overwork (66.6\%), poor ventilation $(54.8 \%)$ and chemical exposure (50.8\%). The most common illnesses were gastro-intestinal problems (57.4\%), backache (56\%), headache (53.2\%) and fatigue/ weakness $(53.2 \%)$. Logistic regression shows association between certain work-related factors and occupational illnesses, and psychosocial problems. Highly significant associations were hearing loss with years spent in the company $(p=0.005)$ and gender $(p=0.006)$; headache and dizziness with poor ventilation $(p=0.000)$; backache with prolonged work $(p=0.003)$. These results will have implications for policy and program formulation for women worker's concerns and issues in the export zones.

\section{P2-442 EUROPEAN ANCESTRY, PHENOTYPIC CHARACTERISTICS AND RISK OF CUTANEOUS MELANOMA: A CASE-CONTROL STUDY IN SAO PAULO, BRAZIL}

doi:10.1136/jech.2011.142976l.72

${ }^{1,2} \mathrm{O}$ Luiz, ${ }^{* 1,3} \mathrm{R}$ Gianini, ${ }^{1} \mathrm{G}$ Francisco, ${ }^{1} \mathrm{~F}$ Toledo, ${ }^{1} \mathrm{~S}$ Souza, ${ }^{1} \mathrm{~J}$ Sanches, ${ }^{1} \mathrm{C}$ Festa-Neto ${ }^{1} \mathrm{G}$ Gattas, ${ }^{1} \mathrm{R}$ Chammas, ${ }^{1} \mathrm{~J}$ Eluf-Neto. ${ }^{1}$ Faculdade de Medicina da Universidade de São Paulo, Sao Paulo, Sao Paulo, Brazil; 'Faculdade de Medicina do ABC, Santo Andre, Sao Paulo, Brazil; ${ }^{3}$ Pontificia Universidade Católica de São Paulo, Sorocaba, Sao Paulo, Brazil

Cutaneous melanoma shows high rates of mortality and its incidence has increased worldwide over the last century. This also is the trend for Brazil. Identified risk factors for melanoma include the pattern of sun exposure, family history of melanoma, number of nevi and phenotypic characteristics. Ethnicity could also influence the outcome of melanomas like European ancestry in different populations. We carried out a hospital-based case-control study in Brazil to evaluate the contribution of phenotypic factors and European ancestry to melanoma risk. A total of 412 subjects (202 